\title{
Projections, Partaken Circuits and Axon Initial Segments of Cortical Principal Neurons
}

\author{
José L. Bueno-López, Juan C. Chara, \\ Juan L. Mendizabal-Zubiaga and Concepción Reblet
}

Additional information is available at the end of the chapter

http://dx.doi.org/10.5772/50191

\section{Introduction}

The axon initial segment (AIS) is the portion of the neuron immediately distal to the axon hillock. The AIS has a specialized membrane that works for a manifold function. The first portion of the AIS membrane possess a collection of ion channels that allows for the modulation of the membrane potential of the parent cell whilst blocking the back propagation of the axon potential. The last portion of the AIS membrane possesses in addition voltagedependent ion channels that are responsible for the ultimate display of the cell, that is, the generation of the axon potential. Much has been investigated recently on the ion channels that are embedded in the AIS membrane of nerve cells. Yet basic parameters such as the length and diameter of the AIS and, of no lesser importance, the number and distribution of boutons synapsing the AIS membrane remains largely unknown for distinct subpopulations of principal cells of cerebral cortex. Principal cells are heterogeneous in many anatomical, molecular and functional aspects but, in agreement with their distinctive possession of combinations of these aspects, they can be classified in different subpopulations. Taking as core features for this grouping the cell laminar address and the pattern of axon projection, this paper reviews subtypes of cerebral cortical principal cells and their AIS features. In doing so, this paper also presents an account of our past and present research on the AIS of principal cells in visual and other areas of cerebral cortex. Yet, aiming to furnish a background to the function of the AIS of cerebral cortical principal cells, we shall begin by reviewing the cellular types and circuits in cortex, and the axon projections arising from the cortex.

\section{Cerebral cortical neurons}

Spiny neurons are of an excitatory nature and most have extrinsic axons, that is, axons that project outside the cortical area where their somata lie. These cells employ glutamate or 
predominantly aspartate as a neurotransmitter (for percentages of aspartergic and glutamatergic cells out of projection cell subpopulations to several telencephalic and extratelencephalic targets, see [1]). By contrast, aspiny neurons are inhibitory, and most of their axons are intrinsic, i.e. they use gamma-amino-butyric acid (GABA) as a neurotransmitter and their axons remain within the cortical area in which the parent cell soma lies. They are usually named interneurons.

\subsection{Interneurons}

Interneurons are present in all cortical areas and layers and represent approximately $10 \%-20 \%$ of cortical neurons in rats [2] or $15 \%-30 \%$ of the total population in other species [3]. Interestingly, while in the occipital, parietal and frontal cortex of the rat the same proportion of GABAergic neurons among all neurons was found (15\%, in [2]), the numerical density of all neurons in the frontal cortex (34,000 per cubic millimetre) was significantly lower than those in the occipital and parietal regions (52,000 per cubic millimetre and 48,000 per cubic millimetre, respectively) [2]. The fixed proportion of interneurons, irrespective of the number of neurons, is in keeping with the idea of the uniformity of cortical circuits. However, this does not exclude the possibility that the proportion of the different types of interneurons might vary in each cortical area, resulting in regional specialization of inhibitory circuits.

Interneurons show great morphological, biochemical and physiological diversity. However, interneurons with the same morphology may have different biochemical characteristics and connectivity [3]. Taken into account this consideration certain interneurons can be recognized by their unique morphological characteristics or they can be more generally divided in subgroups on the bases of their pattern of axonal arborization, synaptic connections (both with pyramidal cells or between themselves) and physiological and biochemical characteristics. One most accepted classification of interneurons is based on the domain of pyramidal neurons their axons target combined with the immunoreactivity for different calcium binding proteins and neuropeptides $[4,5]$.

\subsubsection{Axosomatic targeting interneurons}

The axosomatic targeting interneurons are chandelier cells and basket cells. Chandelier cells target on the AIS of principal cells and basket cells target the somata and proximal portions of dendrites of principal cells. Both interneurons are likely to exhibit a greater impact on the direct output of postsynaptic neurons. An important number of them are fast-spiking interneurons, most of which being immunoreactive for the calcium binding protein parvalbumin. In turn, most parvalbumin-immunoreactive cells are fast spiking large basket cells and chandelier cells. Parvalbumin-immunoreactive cells in rodents account for $40 \%-50 \%$ of GABAergic neurons [6]. A much higher percentage (74\%) was found in macaque visual cortex [7].

Chandelier cells. These cells are the only interneuron that shows clearly recognizable terminal axonal specializations, which form short vertical rows of terminal buttons, resembling candlesticks. These cells only synapse with the AIS of principal cells [8-10]. For this reason they were named axo-axonic cells. Chandelier cells have been found not only in the 
neocortex, but also in several areas of the mesocortex, paleocortex and archicortex, which include the piriform cortex, entorhinal cortex, subiculum, hippocampus, fascia dentata, cingulate cortex, claustrum and amygdala [5,11]. Chandelier cells are present in all cortical layers (except layer 1), most abundantly in layer $2 / 3$ [5,12.13]. A single chandelier cell can innervate between 250 (in neocortex) and 1,200 (in hippocampus) principal cells, indicating the potential to synchronize many principal cells $[5,14]$. Thus, chandelier cells appear ideally suited to shut off entire groups of pyramidal cells, making them the ultimate cortical switches. Each chandelier-terminal innervates single AIS. Moreover, each AIS may be innervated by one or a few chandelier terminals (five or less), which may originate from the same or different chandelier cells (for a review, see [14]). Chandelier cells are parvalbuminreactive and fast-spiking cells.

Basket cells. Basket cells are most difficult to classify for their somatodendritic variety and sizes. The term 'basket' comes from the basket-like appearance of their axonal terminals around pyramidal cell somata that results from convergent innervation by many basket cells. About $50 \%$ of all inhibitory interneurons are basket cells [12]. Basket cells target the somata (15\%-30\% of their synapses are on somata) and proximal dendrites of principal cells; yet basket cells also target somata and dendrites of interneurons, particularly other basket cells $[5,15,16]$. There are small basket cells with a dense local axonal arborization that targets more dendrites than somata of principal cells; these small basket cells predominate in infragranular layers. Large basket cells are the typical basket cells. They have an extensive horizontal axonal branching with few vertical types of collateral. They are therefore the primary source of lateral inhibition across the cortical columns. Large basket cell predominate in layer 2/3. There are intermediate sizes of basket cells too. Basket cells can be parvalbumin-immunoreactive and fast spiking cells $[6,16,17]$. Other subgroup of basket cells are regular spiking; large- and medium-size basket cells are cholecystokinin immunoreactive neurons; small basket cells are immunoreactive for other calcium binding protein, or the vasointestinal neuropeptide; all this depends on the species studied $[6,12,17]$.

\subsubsection{Dendritic targeting interneurons}

The dendritic targeting interneurons are more suited to modify and gate incoming excitatory inputs. The dendritic targeting interneurons are the bipolar cells, Martinotti cells, neurogliaform cells and double-bouquet cells. The latter cells target dendrites and spines.

Double bouquet cells. The axon of a double bouquet cell forms a tight fascicular axonal cylinder that can extends across all layers, innervating distal dendrites and spines. The highly varicose collaterals that form these columnar bundles are unusually thicker than the axonal main stem. While the morphology and distribution of double bouquet cells are similar in the human and macaque neocortex, these cells are modified or less numerous in the neocortex of other species (e.g. the cat), and may even be absent (e.g. the mouse and rat). Thus, differences in the morphology, number and distribution of double bouquet cells may represent fundamental differences in cortical micro organization between primates and other species [3]. Double bouquet cells usually are calbindin-immunoreactive. Together with being calbindin-immunoreactive, they can be also calretinin-immunoreactive. Other double 
bouquet cells are vasointestinal-peptide-immunoreactive and still others, cholecystokininimmunoreactive [3,5,12].

Martinotti cells have a prominent axonal projection to layer 1. They have many fine unmyelinated ascending axon collaterals, which fan out as they ascend, bearing 'en passant' boutons in intermediate layers; some of these collaterals reach and branch as well in layer 1 . Many other interneurons have ascending axon collaterals, but the prominent axonal arbour in layer 1 distinguishes Martinotti cells. Martinotti cells lie in particular in the deep cortical layers but also in layer 3 [18]. The majority of Martinotti cells are somatostatin-immunoreactive.

Bipolar cells. These are small cells with spindle or ovoid somata and narrow bipolar (most often) or bitufted dendrites that extend vertically. These cells can be found in all layers but predominate in layer $2 / 3$ and layer 6 . Bipolar neurons can be excitatory by releasing only vasointestinal-peptide, or inhibitory by releasing mainly GABA (though inhibitory bipolar cells also express vasointestinal-peptide). Bipolar cells commonly express calretinin too. Their axon forms a narrow band that crosses all layers leaving a little proportion of terminals, mainly on the basal dendrites of principal cells [12].

Neurogliaform cells. These are small-sized 'button-type' cells with many fine, radiating dendrites that are short and aspiny, finely beaded and rarely branched. They form a highly symmetrical and spherical dendritic field. The axon can arise from any part of the soma or from the base of a dendrite, and shortly after its origin, it breaks up into a dense, intertwined arborization of ultra-thin axons with as many as ten orders of branching. Fine boutons are distributed on the axonal collaterals to form GABA synapses onto the dendrites of target cells. The molecular characteristics of neurogliaform cells are still not well understood $[3,12]$.

\subsection{Spiny neurons}

In turn, the spiny group of cortical cell consists of several subgroups. Pyramidal neurons with upright somatodendritic orientation are by far the largest subgroup within the group of spiny cells. Upright pyramidal neurons are projecting cells of all cortical layers other than layer 1. Upright pyramidal neurons can be further subdivided (see below). In addition to upright pyramidal neurons, in layers 5-6 there is another collection of projection cells, of spiny nature too, the polymorphic-cell subgroup [19-23]. The spiny stellate neurons of layer 4 are an exception to the spiny-cell/extrinsic-projection correlation, because they are implicated in the canonical thalamo-cortical reciprocal circuit. They are directly innervated by thalamic axons and almost exclusively establish synaptic contact with the neighbouring layer 3 . In this study we consider as a cerebral cortical principal cell any spiny neuron that extends an axon branch outside the cortical area where its soma is located.

\subsubsection{Principal cells of intratelencephalic projection (inclusive of the type I cell, of striatal projection)}

Principal neurons have been sub classified by the laminar position of the cell body, somatodendritic morphology, electrophysiology and axonal target [24]. For a review, see [25]. 
Concerning the axonal target, there are associative neurons of intracortical projection in the same hemisphere and commissural neurons that project to homotopic and heterotopic sites of the opposite hemisphere by way of the corpus callosum and anterior commissure. Principal cells of intratelencephalic projection encompass also those that can extend their axon to the striatum, claustrum, amygdala and other sites that are not out of the telencephalon.

Associative and commissural neurons exist in all layers but with differences concerning projection and species. A limited number of associative and commissural axons arise from spiny stellate cells of layer 4 and low layer 3 [26]. Most associative and commissural axons emerge from pyramidal cells sited in layers $2 / 3$ and 5-6, and also from spiny inverted pyramidal cells and other polymorphic cells of layers $5-6[23,27,28]$. The axons of all these cells extend forward to innervate the layer 4 of cortical areas of higher-order hierarchy [23,27-30]. This is the so-called associative forward projection [31]. In turn, the associative backward projection arise from cells sited in layers $2 / 3$ and 5-6 of higher-order areas to innervate layers 1 and, to a lesser extent, 3, 5 and 6 of areas of lesser-order hierarchy $[23,27,32]$. This layer-segregation of forward and backward projections indicates that they target very different neuronal elements in recipient regions [18].

Spiny inverted pyramidal cells are morphologically and numerically conspicuous among the cells of layers 5-6 furnishing the associative backward projection in rabbits and cats; these cells also originate an important proportion of commissural, cortico-claustral and cortico-striatal projections; they neglegeably project to extratelencephalic centres such as the geniculate nuclei, colliculi and pons [23,27,33]. See Table 1 for a summary and [28] for a review; see also Section 4 in this Chapter for more data on AIS of these cells.

Commissural axons result from a broad and anatomically diverse population of principal cells that are located primarily in layers $2 / 3,5$ and 6 of restricted areas; there are interspecies differences in the laminar address of commissural neurons; in ferrets, rabbits and rats the commissural neurons predominate in infragranular layers [23,26,27,34,35]. Commissural cells can be further defined based on patterns of collateral projections to the ipsi- and contralateral striata and cortices, as well as by the expression of combinations of molecular markers [36].

Despite having common morphologies and similar laminar distributions, the commissural and associative neurons have been reported to differ from each other in the rat, cat, and monkey neocortex; there, at least in adult animals, they constitute two separate populations of neurons that rarely have dual projections [26,34]. The expression of the orphan nuclear receptor Nurr1 is associated to layer 6 neurons projecting to the ipsilateral cortex, but not to those cells projecting to contralateral cortical regions [37]. Recent studies in mice motor cortex show that $4 \%$ of the commissural cells of layer $2 / 3$ and $34 \%$ of layer 5 extends dichotomous axons to ipsilateral prefrontal cortex and contralateral motor cortex [38]. Also, in the rat sensory-motor cortex, there are bifurcated projections to associative and contralateral areas from cells of layers 5-6 [39].

Moreover, certain principal cells of layer 5 of rodents project to the striatum in addition to the ipsilateral and contralateral cortex [40-44]. Cells sited in layer 5 can also project to the ipsi- and 
contralateral claustra in rodents and rabbits $[23,33,43]$. These cortico-claustral cells may branch to the ipsilateral and contralateral cortical areas and striata, in addition to the claustra, but not to the thalamus [43]. By describing genes that identify molecularly distinct subpopulations of commissural neurons, a recent work has cast more light on the heterogeneity of these cells [45].

\begin{tabular}{|l|c|c|c|}
\hline \multicolumn{1}{|c|}{ Projection type } & $\begin{array}{c}\text { Visual } \\
\text { cortex }\end{array}$ & $\begin{array}{c}\text { Auditory } \\
\text { cortex }\end{array}$ & $\begin{array}{c}\text { Retrosplenial } \\
\text { cortex }\end{array}$ \\
\hline Cortico-cortical intrahemispheric projection, total & $25 \%$ & - & Not studied \\
\hline $\begin{array}{l}\text { Cortico-cortical intrahemispheric backward } \\
\text { projection to primary cortex from columns across } \\
\text { cortical layers of secondary cortex }\end{array}$ & $26 \%$ & Not studied & Not studied \\
\hline $\begin{array}{l}\text { Cortico-cortical intrahemispheric backward } \\
\text { projection to primary cortex from a horizontal, } \\
\text { extended cell band along the layer 5/6 border of } \\
\text { secondary and primary cortex* }\end{array}$ & $82 \%$ & Not studied & Not studied \\
\hline $\begin{array}{l}\text { Cortico-cortical intrahemispheric forward } \\
\text { projection to secondary cortex from columns } \\
\text { across cortical layers of primary cortex }\end{array}$ & $7.5 \%$ & $42 \%$ & Not studied \\
\hline $\begin{array}{l}\text { Cortico-cortical intrahemispheric lateral projection } \\
\text { from columns across cortical layers of associative } \\
\text { cortex }\end{array}$ & $31 \%$ & $30 \%$ & Not studied \\
\hline Cortico-claustral projection from primary cortex & $83 \%$ & Not studied & Not studied \\
\hline Cortico-claustral projection from secondary cortex & $23 \%$ & $24 \%$ & Not studied \\
\hline Cortico-claustral projection & - & - & $10 \%$ \\
\hline Cortico-striatal projection & $<20 \%$ & $<20 \%$ & Not studied \\
\hline $\begin{array}{l}\text { Cortico-thalamic projection to lateral and medial } \\
\text { geniculate nuclei }\end{array}$ & Null & Null & Not studied \\
\hline Cortico-collicular projection & Null & Null & Not studied \\
\hline Cortico-pontine projection & $<1 \%$ & Not studied & Not studied \\
\hline
\end{tabular}

Table 1. Percentages of spiny inverted cells of layers 5-6 out of the total number of principal cells of layer $5-6$ of identified projection in cerebral cortex of rabbits $[23,27,33]$ (The commissural projection is not included in this Table, but see [23,27].) All but one* of these percentages were estimated taking into account all infragranular neurons within clear-cut columns of retrograde labelling that extended along the radial dimension of the cortex. $\left.{ }^{*}\right)$ Spiny inverted neurons make up the majority of cells within a horizontal band of cells located at the border between layers 5 and 6 of primary and secondary visual cortex of projection to the ipsilateral primary visual cortex. This band of retrogradely labelled cells extends for millimetres in the secondary visual cortex from the sites of injection of retrograde tracer in the primary visual cortex. This band is particularly cell-populated in brains after multiple injections of tracer; with single injections, labelled cells lie scattered for millimetres in the border between layer 5 and layer $6[27,28]$. These findings have shown that there is a highly convergent yet diffuse projection from the layer 5/6-border principal cells of secondary visual cortex to discrete points of the primary visual cortex. Spiny inverted neurons are the principal source of this type of projection. This widespread projection is distinct from the backward cortico-cortical projection from secondary to primary visual cortex that originates in discrete columnar patches of cells. 
All of these neurons of layer $2 / 3$ and 5 that extend axons to telencephalic centres may be grouped in the type I principal cells upon the condition that they have branches to the striatum [44]. It should be noted, nevertheless, that this name (type I) had been chosen for the neurons of projection to extratelencephalic (or sub-cerebral centres) [1,46], which introduces confusion in the terminology.

\subsubsection{Principal cells of extratelencephalic projection}

The principal cells of extratelencephalic projection typically lie in layers 5-6. They include the projection cells to the thalamus and multiple sites in the brain stem and the spinal cord.

\subsubsection{Principal cells of extratelencephalic projection sited in layer 5 (type II multiple target principal cells and cortico-thalamic cells)}

Cortico-striatal axons of layer 5 cells can be collaterals not only of the type I [44] projection but also of the type II, extratelencephalic projection to regions such as the spinal cord, brain stem nuclei, pontine nuclei, colliculi, substantia nigra, zona incerta and subthalamic nucleus [20,40-44,47]. The latter projection arises from type II cells that in their origin may belong to the same kind of principal neuron with extensive sub-cortical projections that during development looses particularly some of them depending on the cortical area in which the parent soma lies, as it is the instance for the visual cortex [1]. As well, the type II projection leaves driver collaterals to the core cells of higher-order nuclei of the thalamus, which are parvalbumin-positive cells and in turn project to the cortical layer $4[41,44,48]$. Such a branching pattern has been demonstrated for the axonal pathways of visual, somatosensory, pre-limbic and motor cortex of rats, cats and monkeys [41,42,47-51]. The presynaptic boutons of the axon of type II cells of layer 5 are usually of a big size, typically bigger than those leaved by axons of type I intratelencephalic cells $[44,51]$.

Although principal cells share numerous common features within layer 5, they are heterogeneous in their somatodendritic morphology $[1,25,52]$. Type II cells of layer 5 have a thick apical dendrite extending into cortical layer 1 with a prominent terminal tuft; these cells produce distinctive initial bursts of tonic firing in response to current injection [46,5355]. Depending on the cell-body position in layer 5, type I cells are characterized by having an apical dendrite that can tuft in cortical layer 1 or ascend to this layer without tufting; type I cells tend to fire phasically [44,46,54-57]. In addition, cells of layer 5b of short apical dendrite may project to the thalamus and superior colliculus but not to the striatum [18].

Thus, at least three subtypes of principal cells of layer 5 can be tentatively classified in agreement to their projection: the type I cell of intratelencephalic projection; the type II cell of sub-cerebral projection with collaterals to the striatum and thalamus; finally, the corticothalamic cell of layer $5 \mathrm{~b}$, which can project to the superior colliculus but not to the striatum.

\subsubsection{Principal cells of extratelencephalic projection sited in layer 6}

It is well known that some cells of cortical layer 6 innervate the thalamus leaving collaterals to cortical layer 4. This cortico-thalamic projection is originated in pyramidal cells but not in spiny inverted or other polymorphic cells of layer 6 (Table 1) [23,28]. This projection is 
specific of the cortico-thalamo-cortical loop [5,51,58]. Remarkably, the cortico-thalamic projection of layer 6 cells can innervate both types of thalamic relay neurons, i.e. the firstorder (core, parvalbumin-positive) and the higher-order (matrix, calbindin-positive) cells. Both types of relay neurons not only lie in first-order relay nuclei but also higher-order or associative nuclei-the relative number of first-order relay cells being predominant in firstorder relay nuclei and vice-versa. Regardless their thalamic address, the first-order relay cells are driven by ascending axons to the thalamus and successively innervate the spiny stellate cells and small pyramidal cells of layers 4 and $3 \mathrm{~b}$ of precise sites of corresponding cortical areas. The higher-order relay cells widely innervate principal cells of layers 1, 2 and 3a of several cortical areas [48,51]. The first-order relay neurons are driver cells to their innervated cortical cells whereas higher-order relay neurons would be modulator cells to their innervated cortical cells. In turn, cells of layer 6a of cortico-thalamic projection are modulatory cells to the core cells of first- and higher order nuclei of the thalamus whilst leaving collaterals to the thalamic reticular nucleus and cortical layer 4 cells. (It should be remembered here that the type II cells of layer 5 are driving cells to the core cells of the higher-order nuclei of the thalamus and do not leave collaterals to the thalamic reticular nucleus.) Layer $6 \mathrm{~b}$ cells of cortico-thalamic projection innervate the core and matrix cells of first- and higher order nuclei of the thalamus and leave collaterals to cortical layer 5 and 6 layer. By this way, cortical output will influence the synchronous ascending first-order and high order thalamo-cortical pathways. In Ray W. Guillery's words, this is "how anatomical pathways link perception and action" [59]. At least in the visual primary area, the corticothalamic cells of layer 6a dominate numerically over cortico-thalamic cells of layer $6 \mathrm{~b}$. Cortico-thalamic cells of layer 6 have been estimated to be between $30 \%-50 \%$ of all cells of layer 6 neurons (see [60] for review).

\section{Cortical intrinsic circuits}

Principal cells. A solitary action potential in a single principal cell of layer $2 / 3$ can trigger polysynaptic chains of activity, detected as excitatory postsynaptic potentials and inhibitory postsynaptic potentials in recorded neurons [61]. This reveals an extremely efficacious means of activity propagation in the cortical network. In human brain slices, a relatively high proportion of basket (20\%) and chandelier (33\%) neurons could be driven to threshold by a single principal cell spike, in stark contrast to an estimated $1 \%$ likelihood of finding polysynaptic events in rats [61,62]. The fact is that the intralaminar circuit of layer $2 / 3$ is highly recurrent and dominates its own cells. Principal cells of layer $2 / 3$ extend collaterals for several millimetres to form patchy connections in the layer in cats and monkeys $[63,64]$. On the contrary, the intralaminar circuit of layer 5 depends little of the input from its own layer [58]. Intralaminar circuits exist basically on all species studied. However, the weight of the layer $2 / 3$ circuit could be lower in rodents and rabbits because they do not have a patchy pattern connection in layer $2 / 3$ but in layer $5 b-6 a[27,65]$.

Only the type I of principal cells occurs in layer 2/3. These cells extend their axon to the cortex, striatum, claustrum and other telencephalic centres. The probability of reciprocal connections 
between projection subtypes of all of these intratelencephalic cells is similar [57]. In layer 5 there are several types of projection cells. Synapses occur reciprocally between cells of similar type, e.g., intratelencephalic with intratelencephalic cells, type II cells with type II cells, etc. There are connections between type I and type II cells of layer 5 too, but they are hierarchical, that is, projections from type I cells to type II cells are more probable than projections in opposite way [44,54-56]. Principal cells of layer 6 of intratelencephalic projection have a higher probability of extending reciprocal connections between one another than with other type of projection cells. Next, these cortico-cortical cells have a higher probability of extending collaterals to cortico-thalamic cells than vice-versa [60]. Cells of layer 6 receive collaterals from cells of any other layer except layers 2 and 4 and extend collaterals to cells of layers 5-6. The exception being the layer 6 a cell of cortico-thalamic projection to the core cells of thalamic nuclei that also extend collaterals to the thalamic reticular nucleus. This cell originates corticocortical collaterals only to cortical layer 4 cells [60].

Considering all cortical layers, the weight of the local intrinsic circuit in cat and monkey neocortex is estimated to be $80 \%-85 \%$ of excitatory inputs on principal neurons $[58,66]$ whereas the weight of short- and long-range cortico-cortical circuits are $15 \%$ and $3 \%$; on the same cells, the weight of the cortico-thalamic and intriguing cortico-claustral circuits is $1.3 \%$ and $3 \%$ respectively [66]. Finally, although cells of layer $2 / 3$ probably connect more with cells of the same layer, some cells of layer $2 / 3$ send collaterals to both, type I and type II cells of layers 5 and 6 .

Principal cells are approximately $80 \%$ of the total of cortical neurons; interneurons make up the remaining $\approx 20 \%$. Over $71 \%$ of the synapses in the cortex are derived from principal cells. However, this number does not truly reflect the relative balance between excitation and inhibition in cortex. When the larger efficacy of inhibitory synapses is taken into account, the dominance of the principal cells is reduced to $24 \%$. Thus, the spiny cells provide the basic framework of long-distance excitation in both the vertical and lateral dimensions of the cortex, which is moulded by local inhibitory neurons [67].

Interneurons. Cortical interneurons innervate mainly principal cells, but they also innervate interneurons [16]. Interneurons form distinct intralaminar and interlaminar networks $[16,53]$. The probability of reciprocal synaptic connections between principal cells and interneurons varies with the type of interneuron. The intralaminar reciprocal connections between fast-spiking interneurons (chandelier cells and basket parvalbumin-positive cells) and principal cells are significantly higher than the probability of reciprocal connections between non fast-spiking interneurons and principal cells [53]. On the contrary, the interlaminar reciprocal connection between principal cells and interneurons is more frequent with non fast-spiking interneurons [53].

Another distinctive feature of the network of interneurons is its coupling through gap junctions. Electrical coupling of neocortical interneurons is firmly established by anatomical studies and electrophysiological experiments since [68]. The coupling is generally between interneurons of the same type [69]. Chandelier cells are electrically coupled too, as disclosed recently [62]. However, neurogliaform cells are electrically coupled to other neurogliaform 
cells but also to basket cells, regular-spiking interneurons and chandelier cells, among others interneurons. Thus, the neurogliaform cell links networks of particular classes of interneurons, each network being in turn electrotonically coupled itself [70].

Fast-spiking interneurons target the somatic and perisomatic domains of the principal cell; thus, these interneurons strongly regulate the output of the principal cell $[4,18]$. Reciprocal connections between pyramidal cells and fast-spiking interneurons act as a recurrent feedback inhibition that can regulate the timings of pyramidal cell firing [5]. In turn, spike timings of fast-spiking interneurons are correlated with the local field potential in the network of principal neurons during gamma oscillations that depend on the electrical and chemical coupling between fast-spiking, parvalbumin-positive interneurons [17,71]. Parvalbumin-positive basket cells fire counter-phase with principal cells and in the same phase but slightly delayed to chandelier cells $[17,72]$.

\section{The axon initial segment}

Electrically, the AIS bridges dendritic and axonal compartments, converting graded dendritic inputs into all-or-none action potentials. Molecularly, the AIS maintain neuronal polarity preserving the molecular distribution between the axonal and somatodendritic domains [73]. Recent studies have revealed an ever-expanding complexity in the molecular components and in the types and distribution of ion channels embedded in the AIS. This complexity underlies what is now being recognized as a highly dynamic structure [73]. AIS structure and composition vary considerably across, and even within, neuronal classes [74,75], seemingly tuned to the computational demands of the cell. A recent activity of the cell can affect AIS ion channel kinetics and availability, thus altering action potential waveform, timing, and probability. Over long timescales, even the location and size of the AIS can change to compensate for alterations in neuronal activity.

\subsection{Ion channels, anchoring proteins and cytoskeletal components of the axon initial segment}

Ion channels. Although multiple neuronal sites can support action potential generation, the high density of $\mathrm{Na}^{+}$channels inherent to the AIS makes it the lowest threshold site for it. Immunostaining, imaging of spike-dependent $\mathrm{Na}^{+}$flux and electrophysiological studies suggest a similar density of $\mathrm{Na}^{+}$channels throughout the AIS [73,76]. However, a recent study revealed that $\mathrm{Na}^{+}$channels at the distal AIS and the adjacent axon have a much lower half-activation voltage (up to $14 \mathrm{mV}$ ) than those at the proximal AIS and the soma [77]. Accordingly, the use of newly developed voltage imaging techniques combined with careful analysis of the site of initiation and propagation of the action potentials, show that they preferentially initiate at the distal end of the AIS [77-79]. Consistent with these electrophysiological data, immunostaining results revealed a segregation of two $\mathrm{Na}^{+}$ channel subtypes at the AIS: high-threshold Nav1.2 channels and low-threshold Nav1.6 channels, targeted preferentially to the proximal and the distal AIS, respectively [77]. Immunostaining intensity of Nav1.6 peaked at the distal end of the AIS, corresponding well 
to the action potential initiation zone (see [73] for review). Voltage-threshold for action potential initiation seems to be largely determined by the density of $\mathrm{Na}_{\mathrm{v}} 1.6$, whereas $\mathrm{Nav}_{\mathrm{v}} 1.2$ channels in the proximal AIS support action potential back-propagation into the somatodendritic compartment. Indeed, axonal action propagation fails to back propagate when the somatic membrane potential is hyperpolarized [77]. Spike-evoked $\mathrm{Ca}^{2+}$ influx in the AIS of different neurons in the SNC has been revealed by fluorescence imaging techniques [73]. These cells fire spike bursts typified by the recruitment of sub threshold $\mathrm{Ca}^{2+}$ influx through low voltage-activated $\mathrm{Ca}^{2+}$ channels, which include $\mathrm{T}$ - and R-type isoforms [80]. Traditionally, burst evoked $\mathrm{Ca}^{2+}$ influx was thought to be restricted to the dendrites. Indeed, these same low voltage-activated channels mediate $\mathrm{Ca}^{2+}$ influx in the AIS. Since low voltageactivated channels activate at hyperpolarized potentials, they contribute to sub threshold depolarization of the AIS. Thus, their activity can determine when and if a given stimulus evokes an action potential. $\mathrm{Ca}^{2+}$ influx through cartwheel cell T-type channels of the AIS, is down regulated by a type 3 dopamine receptor (D3R)-dependent pathway [81]. This neuromodulatory pathway is remarkably specific for just AIS T-type channels; neither dendritic T-type channels nor AIS $\mathrm{Na}^{+}$or $\mathrm{K}^{+}$channels were affected by D3R signalling [73]. Serotonin1A receptor mediates neuronal hyperpolarization by activating potassium channels in the AIS. In human and monkey neocortex the serotonin 1 A receptor have been reported to be highly concentrated in the membrane of the AIS of principal neurons $[82,83]$.

Associated anchoring proteins and cytoskeletal components. The structure of the AIS of multipolar neurons possesses a dense layer of finely granular material undercoating the plasma membrane, scattered clusters of ribosomes and fascicles of microtubules. The fascicles of microtubules occur only in the axon hillock and initial segment. An undercoating of the plasma membrane of the axon occurs in the node of Ranvier [84-86]. Interestingly, the plasma membrane of AIS and nodes is surrounded by a large extracellular space containing dense material; this similarity between nodes and AIS is coincident with the presence of voltage gated channels and specialization of the cytoskeleton present therein [73,76]. In addition, the dense material undercoating the plasma membrane of the AIS is separated 1525 microns from the internal surface of the AIS membrane [84]. The neuronal cytoskeleton, consisting of interacting spectrins and actins, forms the neuronal structural scaffold and is a spatial delimiter for neuronal membrane proteins; the membrane undercoating is a specialized cytoskeletal element, found only in the AIS. The BIV isoform of spectrin (an actin-binding protein) and ankyrin G (a spectrin-binding protein) mutually confine each other to the AIS [14,76]. Ankyrin G provides a specific anchor for many AIS-specific proteins, including the $\mathrm{Na}^{+}$and $\mathrm{K}^{+}$channel subunits KCNQ2 and 3. PSD-93, other scaffold protein, binds to the $\mathrm{K}_{\mathrm{v}} 1$ channels found at the AIS. In addition $\mathrm{K}_{\mathrm{v}} 1$ channels are associated to the adhesion molecule Casppr2 in the layer $2 / 3$ of the human cerebral cortex [76]. Silencing of PSD-93 expression in cultured hippocampal neurons blocks the recruitment of $\mathrm{K}_{\mathrm{v}} 1$ channels to the AIS but not $\mathrm{Na}^{+}$channels [87]. The AIS is also enriched in the cell adhesion molecules Nr-CAM and Neurofascin-186, and the cytoskeletal linker BIV spectrin [76]. Recruitment of these proteins to the AIS also depends on ankyrin G [73,88]. Together, these results point to ankyrin G as the master regulator of AIS assembly. Silencing of AIS proteins in mature neurons in culture reveals that as for development, ankyrin $G$ is required 
to maintain ion channels at the AIS [89]. Intriguingly, these and other experiments also showed that ankyrin $G$ functions not only to cluster and maintain ion channels, but also to maintain neuronal polarity [89].

\subsection{Length of the axon initial segment}

AIS-length of cortical principal cells ranges between 17-40 microns as counted from the axon hillock $[76,84,86]$. This AIS length approximately coincides with the electrophysiological zone of initiation of the action potential, estimated to be $\approx 35-50$ microns from the soma $[78,79,90,91]$. Interneurons have a shorter AIS than principal cells [15]. Granule cells of the fascia dentata give rise to the smallest unmyelinated fibres of the CNS. In these cells the action potentials are initiated at the distal axon but at $\approx 5-15$ microns from soma with $\mathrm{Na}^{+}$channel density specialized for robust action potential initiation and propagation with minimal current flow [91,92]. The length of the AIS of granule cells of the hippocampus resembled that of the large basket cells of the neocortex, which on average are 6 microns length although the axons of large basket cells are myelinated [15]. Hippocampal granule cells may be an exception because they are not connected between themselves as it occurs in all cortical neurons [5]. It would be of interest to explore if differences in the length of AIS are functionally relevant. In the AIS of hippocampal granule cells the Nav1.6 channel is the predominant alfa-subunit whilst the $\mathrm{Na}_{\mathrm{v}} 1.2$ cannot be detected [92]; this suggests that Nav1.6 channels are enough to generate the axon potential, and therefore that the mechanisms governing this generation are different in the thin non-myelinated axon of the granule cell than in other myelinated or unmyelinated neurons having also a short AIS length.

\section{Study with electron microscopy of the axon initial segment of the inverted variety of cerebral cortical principal cell (of intratelencephalic projections)}

Our studies following the use of retrograde tracers in cerebral cortex of rats, rabbits and cats showed that spiny inverted neurons of layers 5 and 6 originate intra-telencephalic projections $[23,27,28,33]$. Spiny inverted neurons are odd because of having not only circumscribed projections and an inverse somatodendritic orientation but also for the sites from which their axon arises. As seen with Golgi-method impregnation, retrograde tracers and intracellular filling (for a review, see [28]), these cell sites may be (1) the basal surface of the soma, or even the basal dendrite portion next to the soma, (2) the (lateral) surface of the soma and (3) the apical dendrite, sometimes from a sector more remote from the soma than the emergence site of the first dendrite branching [23]. Of the 127 Golgi-impregnated spiny inverted neurons in the occipital and temporal cortices of rabbits which we examined, $29 \%$ of the axons arises from (1), 9.5\% from (2) and 61.5\% from (3) [23]. This distribution is similar to that in rat visual and sensory-motor cortices [28]: of 28 Golgi-impregnated spiny inverted neurons, 32\% of the axons emerges from (1), $21.5 \%$ from (2) and $46.5 \%$ from (3). Hence, the probability of axon emergence from the apical dendrite is higher both in rabbits and rats. There, inputs on the apical dendrite and its branches can be more operational for the generation of cell outputs, as they do not pass 
the somatic robust inhibitory barrier; in turn, the back-propagation of a generated axon potential can more effectively result in changes of the membrane potential of the apical dendrite and its branches. Thus, two physically segregated input integrations may simultaneously operate in the cells in which the axon arises from the apical dendrite: one at the immediate apical-tree membrane domain, the other at the somatic and remaining dendritic membrane domain. In the cat visual cortex, the orientation of apical dendrites of a spiny inverted neuron depends on the position of the parent cell within the gyri [28]. Accordingly, the incidence of truly reversed spiny inverted neurons decreased from the top of the gyri to the bottom of the sulci, while that of almost horizontally orientated pyramidal neurons increased. Most axons were found to arise from the apical dendrite or from one of its first branches in cat spiny inverted neurons too.

We reconstructed by means of electron-microscopy serial photography the AIS of eleven spiny inverted neurons of unknown projection (though they probably were cortico-cortical. corticoclaustral, or cortico-striatal, see Table 1). The length of the AIS of these neurons ranged between 32.0 and 101.2 microns, and its thickness varied between 0.58 and 1.04 microns. The range of the AIS length described by others shows some variability, indicating that cells of different subtypes of projection neurons, or cells within the subtypes themselves, may have different AIS length; e.g. the commissural and cortico-thalamic cells show more variability in the length of the AIS than the cortico-cortical associative ones [86]. Importantly, the number of synaptic boutons received by the AIS of spiny inverted neurons was found to be 24.4 on the average, but the range was also wide (11-37 boutons). Analysis of the spiny inverted neurons as classified in terms of the emergence site of the axon revealed that AIS which proceed from the apical dendrite were the shortest, thinnest and less innervated, whereas AIS arising from the somatic flank were the longest, widest and most innervated. Thus, AIS originated on apical dendrites averaged a length of 38.8 microns (range 37.1-45.4 microns), a diameter of 6.0 microns (range 0.58-0.62 microns) and a number of 15 apposed boutons (range 11-18 boutons). AIS of lateral somatic emergence averaged a length of 95.5 microns (range 93.2-97.8), a diameter of 1.04 microns (range 1.04-1.04) and 34 boutons (range 31-37). In turn, six AISs of somatic basal emergence averaged 60.9 microns in length, 0.83 microns in diameter and 26 boutons (ranges being 32.0-101.2 microns, $0.71-0.96$ microns and $21-29$ boutons, respectively) [28]. These features of the AIS may support an output generation that is peculiar to subclasses of spiny inverted neurons. Work is currently in progress in our laboratory to refine to which extent differences in the number of synapses received by the AIS are related to the type of axon projection of spiny inverted cells.

\section{Study with electron microscopy of the axon initial segment of the upright variety of cerebral cortical principal cell with experimentally identified backward ipsilateral and commissural projections in visual cortex}

We present in the following a preliminary report on AIS of twelve pyramidal neurons of cortico-cortical projection to primary visual cortex; these cells, amid other projection cells, 
were recently studied in our laboratory [93]. All these twelve cells had a typical upright somatodendritic orientation; they sited in the lateral partition of secondary visual cortex of rats (Figure 1). The axons of six of these neurons projected to the ipsilateral primary visual cortex that bears the cortical representation of the vertical central meridian of binocular visual field. The axons of the remaining six neurons projected to the same region of primary visual cortex but contralaterally through the callosum. In each of these two groups, three neurons lay in layer 3 and the remaining three in layer 5 . Thus, the neurons reported here were distributed in four subgroups in agreement with their layer address and corticocortical projection.

A.

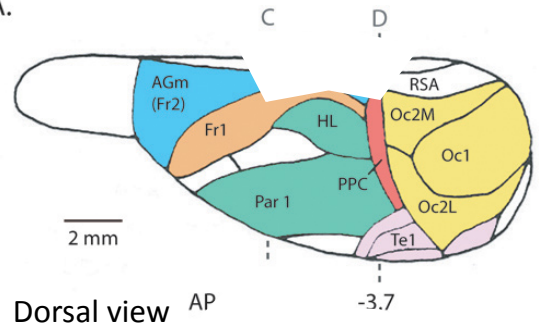

C.

$* \mathrm{AGm}$
B.

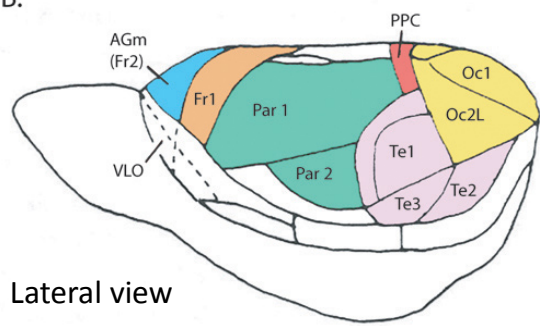

D.

Figure 1. Schematic drawings of the dorsal view (A) and lateral view (B) of the left hemisphere of rat cerebral cortex. Oc1 corresponds with the primary visual area; Oc2M and Oc2L do so with the medial and lateral parts of the secondary visual area, respectively. The border between Oc1 and Oc2L is the cortical representation of the vertical central meridian of binocular visual field. Biotinylated dextranamide (BDA) microinjections were placed in the Oc1 side of this border. Cells labelled with BDA by retrograde axon transport were taken from the ipsilateral Oc2L and homotopic contralateral border between Oc1 and Oc2L.

\subsection{Material and methods}

To study all these twelve neurons we combined axon track-tracing methods and serial electron microscopy. We injected biotinylated dextran-amide (BDA) in primary visual cortex, in order to identify projection pyramidal neurons under light microscopy (Figures 1, 2); then, we performed serial ultrathin-cutting and -photography to study anatomical parameters of labelled AISs under electron microscopy (Figures 3-5). Studied AIS parameters were length, thickness, and number of apposed synaptic boutons and distribution of these boutons along the AIS membrane. Student's t tests ( $p$-value $\leq 0.05$ ) and linear regressions statistics were used to compare measured AIS parameters (simple linear regression and non-parametric multiple tests; $\mathrm{p}$-value $\leq 0.05$ ). 

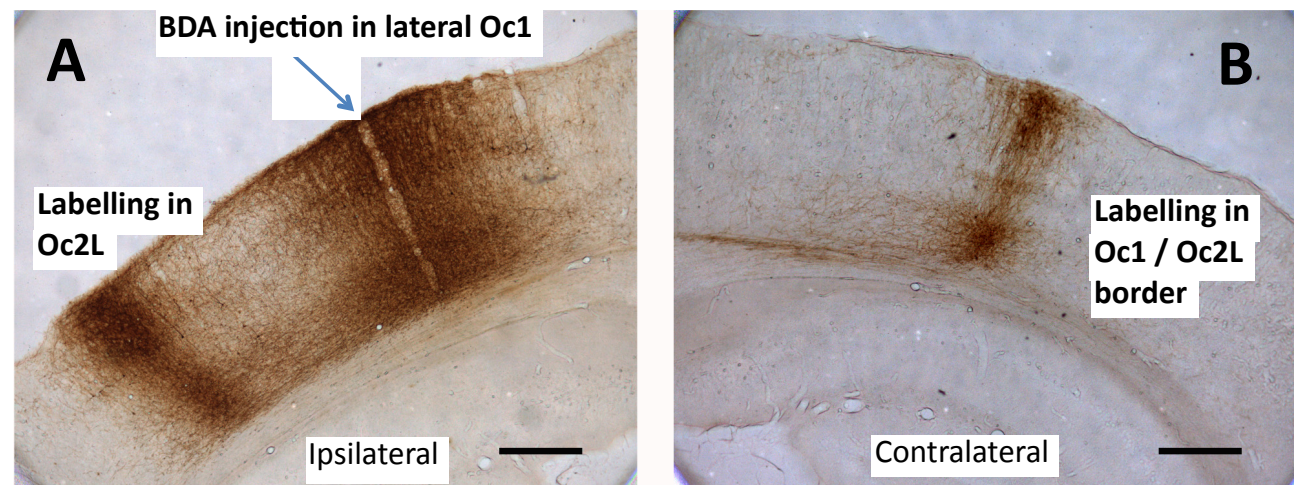

Figure 2. Microphotographs of paired coronal sections of left $(\mathrm{A})$ and right $(\mathrm{B})$ hemispheres of rat visual cerebral cortex. See columns of labelling in ipsilateral Oc2L (lateral partition of secondary visual area) and contralateral border between Oc2L and Oc1 after a biotinylated dextran-amide (BDA) microinjection (blue arrow) in Oc1 (primary visual area). Projection cells were selected for the present study among BDA-labelled cells of these or similar columns following comparable injections of BDA in other rats. Scale bars, 500 microns.

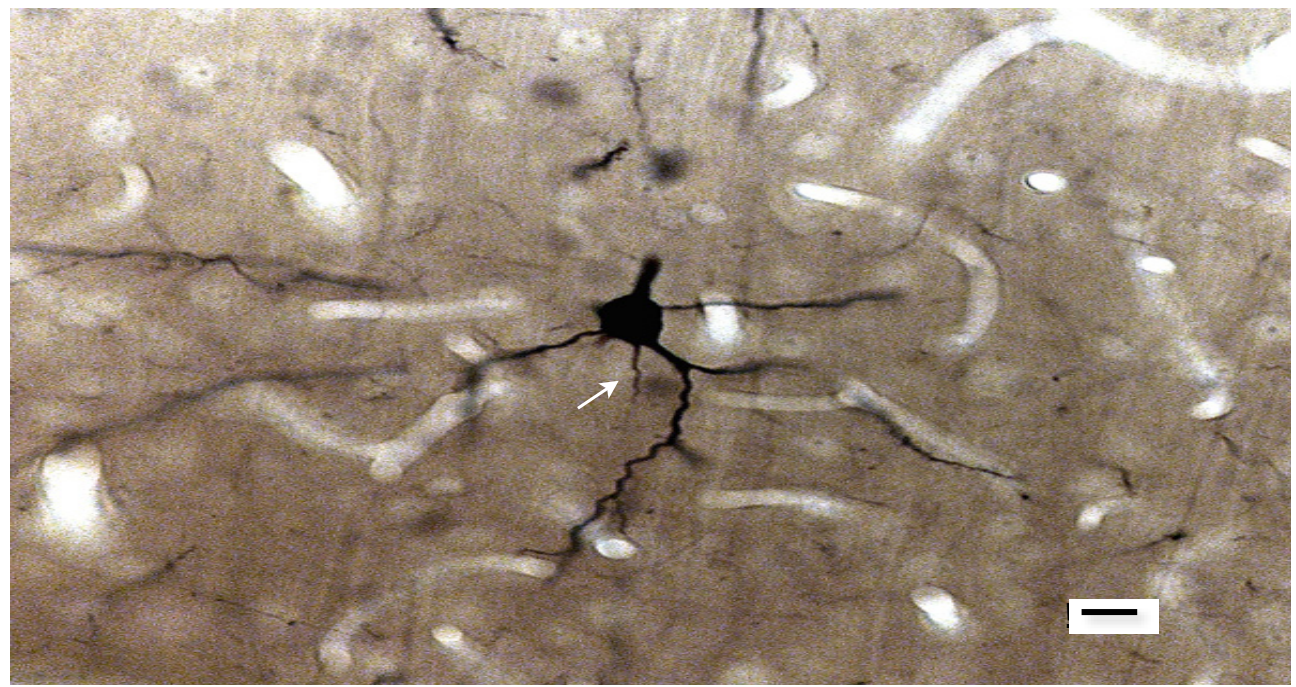

Figure 3. Microphotograph of a cell sited in layer 3 of Oc2L (lateral partition of secondary visual area); the cell was labelled after a biotinylated dextran-amide injection to ipsilateral Oc1 (primary visual area) in the cerebral cortex of a rat. The cell was flat embedded and the resultant slice was glued on top of a resin capsule. The axon initial segment (arrow) underwent serial ultrathin cutting and then it was examined under electronic microscopy. Scale bar, 15 microns. 


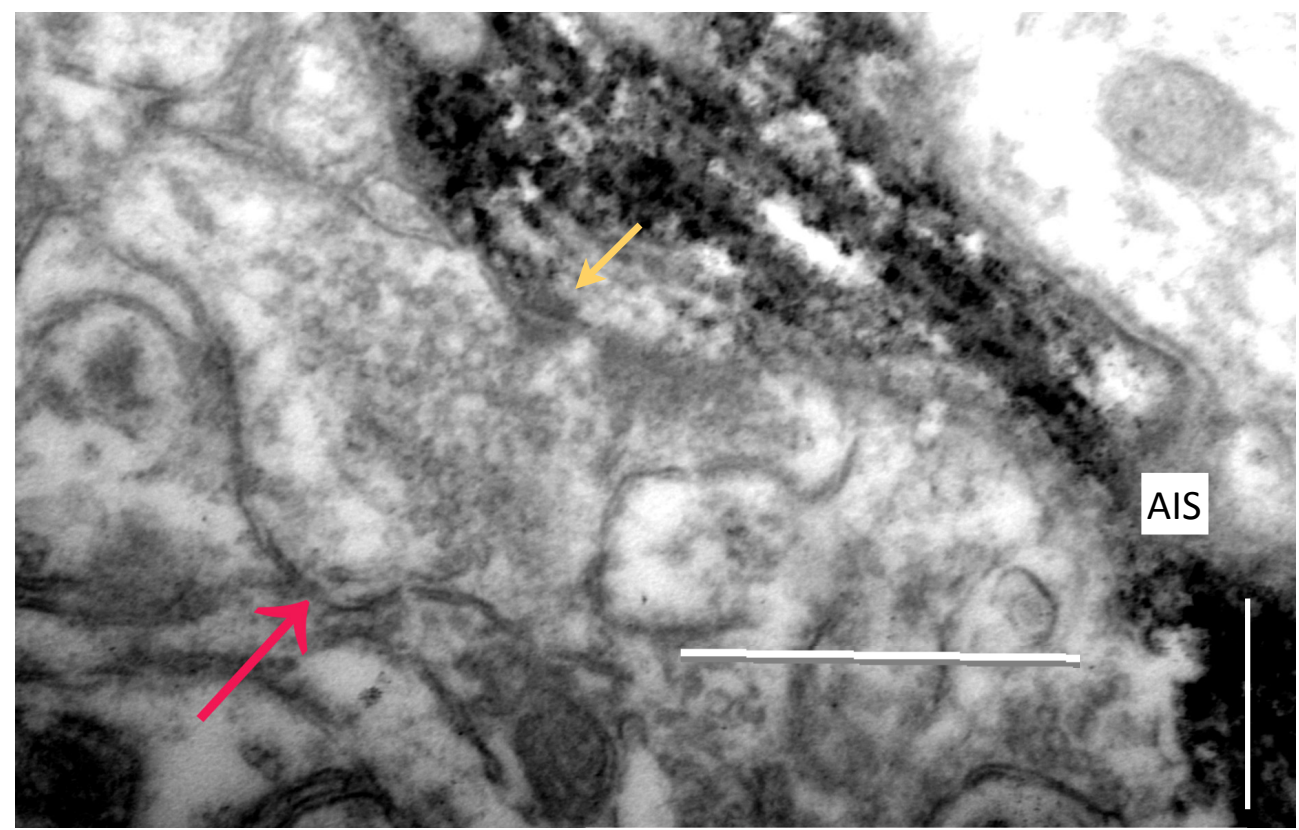

Figure 4. Electron-microscopy photograph of an axonal bouton (between red and yellow arrows) synapsing on the axon initial segment (AIS) of the cell shown in Figure 3. Most other boutons synapsing on this and other AIS contained flat vesicles. AIS was occupied by biotinylated dextran-amide, which gave it its black, grainy aspect. Notwithstanding this filling, see the pre- and postsynaptic densities, which are pointed at by the yellow arrowhead. Scale bar, 0.5 micron.

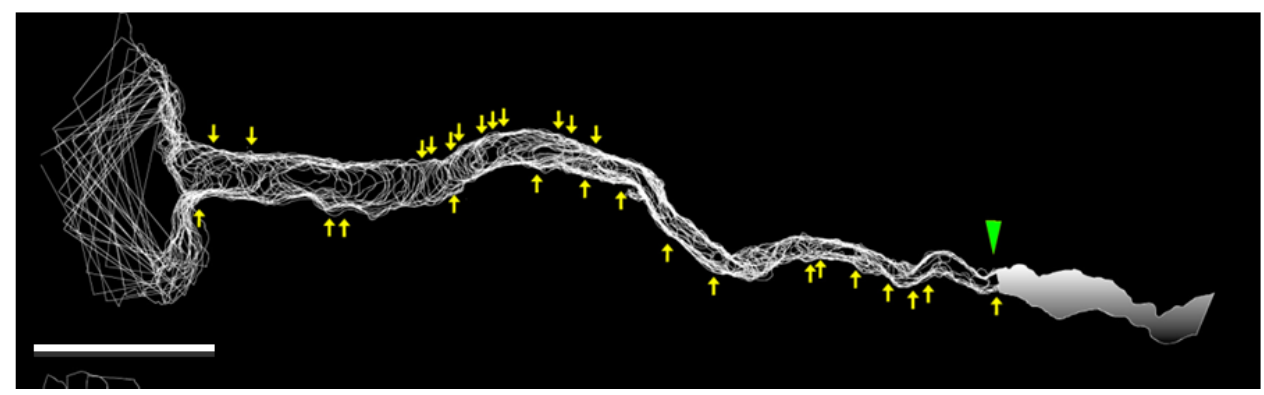

Figure 5. Electron-microscopy serial reconstruction of the axon initial segment (AIS) of the cell shown in Figures 3-4. The cell sited in layer 3 and furnished the associative backward projection to most-lateral (next to the border with lateral secondary cortex) primary visual cortex. The AIS was 22.27-micron-long, averaged a diameter of 0.93 microns and received 28 synaptic boutons (yellow arrows). Note the uneven distribution of these boutons along AIS: boutons were more abundant in the central tier and then in the distal one. Not all studied neurons in [93] and reported here had this bouton distribution along their AIS. The green arrowhead points to the site at which the myelin sheet begun. Scale bar, 5 microns. 


\subsection{Results}

As a group, upright principal cells furnishing the associative backward projection from ipsilateral lateral secondary visual area to most-lateral primary visual area in the rat cerebral cortex had, on the average, shorter and thicker an AIS than similar cells of projection to the same area but through the callosum; these differences were however non-significant (Box 1). Importantly, AIS of cells of the associative backward projection averaged more synaptic boutons than AIS of cells of projection through the callosum; thus, the synaptic-bouton density per AIS length-unit was higher for AIS of cells of the associative backward projection; these differences were significant (Box 1).

Results also showed that the neurons sited in layer 3 had, on the average, shorter and thinner an AIS than the neurons sited in layer 5, these differences being non-significant except for the AIS-length comparison. Importantly, the AIS of layer 3 cells averaged more synaptic inputs than that of layer 5 cells; thus, the bouton density per AIS length-unit was higher for layer 3 cells. These differences were significant (Box 1).

\section{AVERAGED VALUES OF PYRAMIDAL-NEURON AIS AND THEIR COMPARISON AS GROUPED BY AXON PROJECTION}

\begin{tabular}{|c|c|c|c|c|c|}
\hline Projection & Neurons & $\begin{aligned} & \text { AIS Lenght }(\mu \mathrm{m}) \\
\pm & \text { Standard Deviation }\end{aligned}$ & $\begin{array}{c}\text { AIS } \emptyset(\mu \mathrm{m}) \\
\pm \text { Standard Deviation }\end{array}$ & $\begin{array}{l}\text { Number of Boutons } \\
\pm \text { Standard Deviation }\end{array}$ & $\begin{array}{l}\text { Syn. Bouton Density } \\
\text { per AIS Lenght }(\mu \mathrm{m})\end{array}$ \\
\hline Ipsilateral & 6 & $26.73 \pm 5.08$ & $0.98 \pm 0.10$ & $26 \pm 5.25$ & $1.02 \pm 0.33$ \\
\hline & \multicolumn{5}{|c|}{ AS GROUPED BY SOMA LOCATION } \\
\hline Layer 3 & 6 & $24.50 \pm 4.01$ & $0.92 \pm 0.13$ & $25.50 \pm 5.75$ & $1.06 \pm 0.28$ \\
\hline Layer 5 & 6 & $30.61 \pm 2.91$ & $1.02 \pm 0.12$ & $18.50 \pm 3.62$ & $0.62 \pm 0.17$ \\
\hline
\end{tabular}

Differences between values in gray boxes were statiscally significant (Student's t-test, $p<0.05$ )

Box 1. Averaged values of AIS parameters and their comparison as grouped by projection and layer address.

In human cortex, the length of AIS of layer 3 neurons ranges between 11-47 microns, as calculated by immunocytochemistry to BIV spectrin, GAT-1 and $\mathrm{Na}^{+}$channels [76]. However the length of the AIS is not correlated with the size of the perykarion [84,86, but see 94]. By means of regression tests we compared (a) the lengths versus the diameters, and (b) the lengths versus the numbers of received synaptic boutons for the twelve separate AIS presented here. The first comparison revealed a linear and significant relation ( $p$-value = 0.009 ), by which the AIS diameter variation explained the $52 \%$ the AIS length variation. The second comparison, i.e. the lengths versus the numbers of received synaptic boutons, revealed an inverse, non-significant relation ( $\mathrm{p}$-value $=0.136$ ). With a non-parametric multiple regression test we compared for the twelve AIS, as taken separately, the numbers of received synaptic boutons versus the layer addresses of the parent cell somata and the projection of the on-going axons. Direct and highly significant correlations emerged from these comparisons (p-values being $9.3 \times 10^{-5}$ and 0.00025 , respectively). Thus, AIS with a high 
number of apposed synaptic boutons has up to $90 \%$ of probabilities of being part of a cell sited in layer 3 , on the one hand, or projecting backwards to the primary visual cortex, on the other hand.

Though the number of measured cells in the present study is admittedly low, we believe it is satisfactory for an electron microscopy study. The numbers of synaptic boutons on AIS of upright principal cells of cortico-cortical projection reported here are in general agreement with others of different cortical areas and mammals, if differences between animals, area addresses and axon projections have to be taken into account. Major discrepancies are with cat visual cortex [85] and monkey sensory-motor cortex [95] (Table 2). It has to be said however that the number of boutons revealed for the cat visual cortex in [85] exceeds by a large amount the number of boutons found for the cat visual cortex in [96] and in [86]though in [86] the layer address of the cells must be considered too. More quantitative studies on AIS innervation of subtypes of principal cells of identified axon projection in different animals and cerebral cortical areas are clearly needed.

\begin{tabular}{|l|l|l|l|l|l|}
\hline Reference & Animal & Type of cortex & $\begin{array}{l}\text { Layer }- \\
\text { projection }\end{array}$ & Cells & Boutons \\
\hline$[96]$ & Cat & Visual & $2 / 3-$ unknown & 18 & 24 (average) \\
\hline$[85]$ & Cat & Visual & $2 / 3-$ unknown & 3 & $42-44$ \\
\hline$[86]$ & Cat & Area 17 & $2 / 3-{ }^{*}$ a & 18 & $16-28^{*_{a}}$ \\
\hline$[95]$ & Monkey & Sensory-motor & $\begin{array}{l}2 / 3-\text { callosal }(2 \\
\text { cells) and } \\
\text { unknown }\end{array}$ & 8 & $2-52$ \\
\hline$[93]$ & Rat & Visual & $2 / 3-{ }^{* \mathrm{~b}}$ & 6 & $19-34^{* \mathrm{~b}}$ \\
\hline$[95]$ & Monkey & Sensory-motor & $5-$ unknown $^{-}$ & 8 & $2-26$ \\
\hline$[28]$ & Rat & Visual & $5 / 6-{ }^{+}$ & 11 & $11-37^{+}$ \\
\hline$[93]$ & Rat & $\begin{array}{l}\text { Visual, secondary } \\
\text { \& primary }\end{array}$ & $5 / 6-{ }^{*}$ & 6 & $15-23^{*_{\mathrm{c}}}$ \\
\hline$[97]$ & Rabbit & Visual & $5-{ }^{* *}$ & 1 & $10^{* *}$ \\
\hline$[86]$ & Cat & Visual & $5-{ }^{* * *}$ & 10 & $1-5^{* * *}$ \\
\hline
\end{tabular}

Table 2. Comparison between numbers of synaptic boutons apposed to the AIS membrane as found in [93] and other studies. Note that the boutons seen on AIS of axons projecting to the thalamus and the colliculi are far fewer than those seen on AIS of axons projecting to intratelencephalic projections. Differences concerning types of projection: $\left({ }^{*}\right)$ cortico-cortical. (a) Contralateral projection from primary visual area to secondary visual area, 16-23 boutons; ipsilateral projection from primary visual area to secondary visual area, 22-28 boutons. (b) Contralateral projection from primary visual area to the border between primary visual area and lateral secondary visual area, 19-22 boutons; ipsilateral projection from lateral secondary visual area to the border between primary visual area and lateral secondary visual area, 28-34 boutons. (c) Contralateral projection from primary visual area to the border between primary visual area and lateral secondary visual area, 15-16 boutons; ipsilateral projection from lateral secondary visual area to the border between primary visual area and lateral secondary visual area, 2023 boutons. ${ }^{* *}$ Cortico-collicular projection. ${ }^{* * *}$ Cortico-thalamic projection. Difference concerning anatomical subtypes of principal cells: + Spiny inverted neuron AIS. 

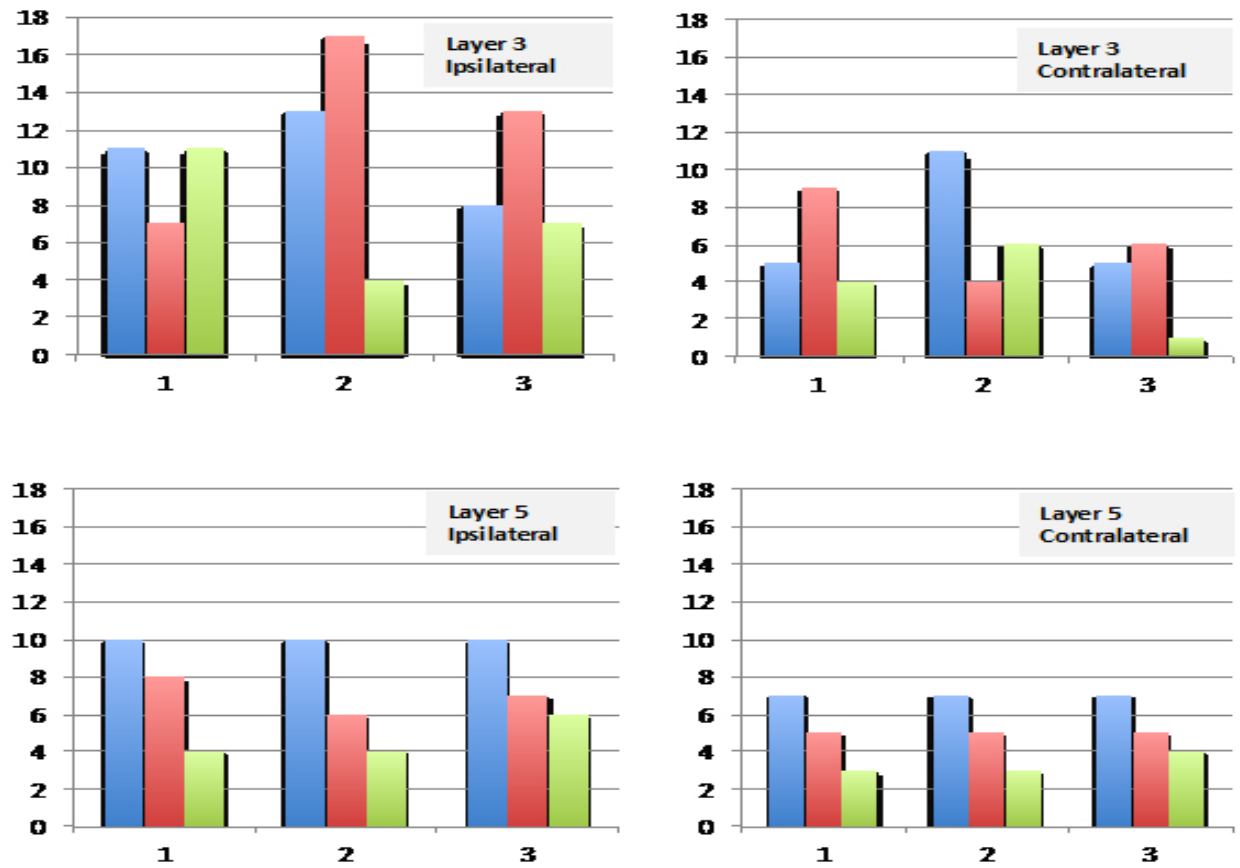

Figure 6. Distribution of synaptic boutons along each of twelve AIS of the present study [93]. Cells sited either in layer 3 or layer 5 and furnished either the associative backward (ipsilateral) projection or the callosal (contralateral) projection, both to primary visual cortex (3 neurons per layer and projection). Each AIS was divided into three segments of equal length (blue bars, closest tiers to the cell somata; green bars, closest tiers to the axon). X-axes show the bouton distribution for each AIS. Y-axes show the number of boutons counted per tier per AIS. Notice that, whilst all six AIS of layer 5 cells had a comparable decreasing pattern, AIS of layer 3 cells had uneven distributions even among cells of the same axon projection.

In order to know on the distribution of synaptic boutons along AIS, we divided each of the twelve AIS reported here in three equal longitudinal tiers and then we assigned boutons to tiers. As averaged for layer addresses and axon projection cell-subgroups, the distribution was decreasing towards the axon but for the subgroup of layer 3 cells of associative backward (ipsilateral) projection; there, the intermediate tier had more boutons (not shown). Most importantly, we compared one another the AIS of the twelve neurons (Figure 6). Then different patterns emerged not only for cells sited in layer 3 of ipsilateral projection but also for cells sited in layer 3 of commissural projection. Still, each cell sited in layer 5 had the decreasing pattern, notwithstanding if the cell was of ipsilateral or contralateral projection. Cells of layer 3 had uneven distributions, which can be tentatively grouped in two presumptive patterns: a 'reel' one, with more boutons apposed to the proximal and distal tiers of the AIS, and a 'barrel' type, with less boutons on the intermediate tier (Figure 6).

The variety in the distribution observed for the principal cells of layer 3 suggests either the presence in this cell group of examples of minor cell subpopulations occurring within those 
studied in [93], or activity-dependent AIS plasticity, or both. Ion channels composition at the AIS can vary considerably across different neuronal types [74] and diversity in the AIS length and position in the axon may also underlie interneuron variation in firing properties. For example, classes of retinal ganglion cells with different visual properties have initial segments that differ in length, and in their position within the axon [98]. In the avian magnocellularis and laminaris nuclei, which are respectively the second- and third-order nuclei in the auditory pathway [99], the length and the location of the AIS vary with the tuning frequency of neurons [100]. Activity-dependent AIS plasticity has been observed in cultured hippocampal neurons. Increasing chronically neuronal activity over 48 hours resulted in a significant shift in AIS position with the entire structure (ankyrin G, BIV spectrin, and $\mathrm{Na}^{+}$channels) moving distally away from the soma [75]. Importantly, hippocampal AIS relocation is a bidirectional phenomenon because the AIS can shift proximally after neurons are returned to baseline activity conditions. In this way, on-going neuronal activity can fine-tune AIS position. Moreover, a lack of auditory input causes a change in AIS length of neurons of chick auditory nucleus magnocellularis [101]. All these studies showed that the AIS plasticity is coupled with changes in neuronal excitability. The distinct length of the AIS of hippocampal pyramidal neurons $(\approx 30$ microns) and the neurons of the nucleus magnocellularis ( $\approx 10$ microns) has been suggested to be the cause of these different plastic changes in the AIS. Indeed, cell type-based variability in AIS plasticity is seen within hippocampal cultures, where GAD 65-expressing interneurons display little or no shift in AIS location upon high potassium stimulation [75]. Dopaminergic neurons in dissociated cultures of rat olfactory bulb show inverse AIS plasticity: their initial segments move proximally after 48 hours depolarization.

Although these plastic changes have not been shown for neocortical neurons to the best of our knowledge, nor is clear to which extent are associated with shifts on the distribution of presynaptic boutons apposed to the membrane of the AIS, it will be fascinating in the future to see how different types of neuron of diverse brain regions use different forms of AIS plasticity in response to perturbations in their electrical activity. Nonetheless, it follows from our study that at least for associative and commissural projections to primary visual cortex in the rat, the innervation of AIS of principal cells of typical somatodendritic orientation is steadier in layer 5 than in layer 3.

\section{Conclusion}

By presenting data on parameters such as the length and diameter of the AIS and, of no lesser importance, the number and distribution of presynaptic boutons apposed to the AIS membrane, this study advances the knowledge on the control of membrane potential and initiation of axon potential of visual cortex neurons, and particularly of the principal cells with cortico-cortical axon projection from layers 3 and 5 to primary visual area. It unveils that the bouton density on the AIS of principal cells would correlate significantly with the layer address and axon projection of the parent neuron rather than with the length and thickness of AIS proper. The present study additionally shows that there was a repeated decrease in the number of synaptic boutons apposed along the AIS of neurons of layer 5 but 
not of layer 3. It might be that neurons of layer 3 can be subdivided in subgroups within the groups of cortico-cortical ipsilateral or contralateral projection we have considered in the study. These subgroups might possess undisclosed structural and functional cell features associated to permanent or transitory synaptic-bouton distributions along the AIS.

\section{Author details}

José L. Bueno-López ${ }^{*}$ Juan C. Chara, Juan L. Mendizabal-Zubiaga and Concepción Reblet Department of Neurosciences, School of Medicine and Dentistry, The University of the Basque Country (UPV/EHU), Campus of Leioa (Bizkaia), Spain

\section{Acknowledgement}

This work was funded by grants GIU07/14 and UFI11/41 of UPV/EHU.

J.L.B.-L. and C.R. wish to lovingly dedicate this work to Laína H.B, Julia B.R. and Juan H.S. for leaving their mark on us ("Todo pasa y todo queda, / pero lo nuestro es pasar, / pasar haciendo caminos, / caminos sobre el mar // ... // Caminante, son tus huellas / el camino y nada más; / caminante, no hay camino, / se hace camino al andar. // Al andar se hace camino / y al volver la vista atrás / se ve la senda que nunca / se ha de volver a pisar. // Caminante no hay camino / sino estelas en la mar... ", Antonio Machado, Proverbios y Cantares, 1909).

\section{References}

[1] Molnár Z, Cheung, AFP. Classification of subpopulations of layer V pyramidal projection neurons. Neuroscience Research 2006; 55(2) 105-115, doi:10.1016/j.neures.2006.02.008

[2] Beaulieu C. Numerical data on neocortical neurons in adult rat, with special reference to the GABA population. Brain Research 1993; 609(1-2) 284-292, doi:10.1016/00068993(93)90884-P

[3] DeFelipe J, Alonso-Nanclares L, Arellano JI. Microstructure of the neocortex: comparative aspects. Journal of Neurocytology 2002; 31(3-5) 299-316, doi:10.1023/A:1024130211265

[4] DeFelipe J. Cortical interneurons: from Cajal to 2001. Progress in Brain Research 2002; 136(Chapter7) 215-238, doi:10.1016/S0079-6123(02)36019-9

[5] Somogyi P, Tamás G, Luján R, Buhl EH. Salient features of synaptic organisation in the cerebral cortex. Brain Research Reviews 1998; 26(2-3)113-35, doi:10.1016/S01650173(97)00061-1

[6] Burkhalter A. Many specialists for suppressing cortical excitation. Frontiers in Neuroscience 2008; 2(2) 155-167, doi:10.3389/neuro.01.026.2008

[7] DeFelipe J, González-Albo MC, Del Río MR, Elston GN. Distribution and patterns of connectivity of interneurons containing calbindin, calretinin and parvalbumin in visual

${ }^{*}$ Corresponding Author 
areas of the occipital and temporal lobes of the macaque monkey. Journal of Comparative Neurology 1999; 412(3) 515-526, doi:10.1002/(SICI)10969861(19990927)412:3<515::AID-CNE10>3.0.CO;2-1

[8] Szentágothai J, Arbib MA. Conceptual models of neural organization. Neurosciences Research Program Bulletin 1974; 12(3) 306-510.

[9] Jones EG. Varieties and distribution of non-pyramidal cells in the somatic sensory cortex of the squirrel monkey. Journal of Comparative Neurology 1975; 160(2) 205-267, doi:10.1002/cne.901600204

[10] Somogyi P. A specific 'axo-axonal' interneuron in the visual cortex of the rat. Brain Research 1977; 136(-) 345-50.

[11] Inda MC, DeFelipe J, Muñoz A. Morphology and distribution of chandelier cell axon terminals in the mouse cerebral cortex and claustroamygdaloid complex. Cerebral Cortex 2009; 19(1) 41-54, doi:10.1093/cercor/bhn057

[12] Markram H, Toledo-Rodríguez M, Wang Y, Gupta A, Silberberg G, Wu C. Interneurons of the neocortical inhibitory system. Nature Reviews Neuroscience 2004; 5(-) 793-807, doi:10.1038/nrn1519

[13] Inda MC, DeFelipe J, Munoz A. The distribution of chandelier cell axon terminals that express the GABA plasma membrane transporter GAT-1 in the human neocortex. Cerebral Cortex 2007; 17(9) 2060-2071, doi:10.1093/cercor/bhl114

[14] Howard A, Tamás G, Soltesz I. Lighting the chandelier: new vistas for axo-axonic cells. Trends in Neurosciences 2005; 28(5) 310-316, doi:10.1016/j.tins.2005.04.004

[15] DeFelipe J, Hendry SHC, Jones EG. A correlative electron microscopic study of basket cells and large gabaergic neurons in the monkey sensory-motor cortex. Neuroscience 1986; 17(4) 991-1009, doi:10.1016/0306-4522(86)90075-8

[16] Kisvárday ZF, Beaulieu C, Eysel UT. Network of gabaergic large basket cells in cat visual cortex (area 18): implication for lateral disinhibition. Journal of Comparative Neurology 1993; 327(3) 398-415, doi:10.1002/cne.903270307

[17] Freund T. Interneuron diversity series: rhythm and mood in perisomatic inhibition. Trends in Neurosciences 2003; 26(9) 489-495, doi:10.1016/S0166-2236(03)00227-3

[18] Thomson AM, Bannister AP. Interlaminar connections in the neocortex. Cerebral Cortex 2003; 13(1) 5-14, doi:10.1093/cercor/13.1.5

[19] Ramón y Cajal S (1891) On the Structure of the Cerebral Cortex of Certain Mammals. (La Cellule 7: 125-176). In: DeFelipe J, Jones EG (trans. and eds.) Cajal on the Cerebral Cortex: An Annotated Translation on the Complete Writings (History of Neuroscience; № 1). New York: Oxford University Press; 1988, p23-54.

[20] Ramón y Cajal, S. (1911). Histologie du Systéme Nerveux de l'Homme et des Vertebrés. Paris: Maloine (Madrid: C.S.I.C. Facsimile Edition 1972). Chapters 24-35.

[21] Van der Loos H. The 'improperly' oriented pyramidal cell in the cerebral cortex and its possible bearing on problems of neuronal growth and cell orientation. Bulletin Johns Hopkins Hospital 1965; 117(-) 228-250.

[22] DeFelipe J, Jones EG. The Functional Histology of the Cerebral Cortex and the Continuing Relevance of Cajal's Observations. In: DeFelipe J, Jones EG (trans. and eds.) 
Cajal on the Cerebral Cortex: An Annotated Translation on the Complete Writings (History of Neuroscience; № 1). New York: Oxford University Press; 1988, p557-621.

[23] Bueno-López JL, Reblet C, López-Medina A, Gómez-Urquijo S, Grandes P, Gondra J, Hennequet L. Targets and laminar distribution of projection neurons with inverted morphology in rabbit cortex. European Journal of Neuroscience 1991; 3(5) 415-430, doi:10.1111/j.1460-9568.1991.tb00829.x

[24] Larkman A, Mason A. Correlations between morphology and electrophysiology of pyramidal neurons in slices of rat visual cortex. I. Establishment of cell classes. Journal of Neuroscience 1990; 10(5) 1407-1414.

[25] DeFelipe J, Fariñas I. The pyramidal neuron of the cerebral cortex: morphological and chemical characteristics of the synaptic inputs. Progress in Neurobiology 1992; 39(6) 563-607.

[26] Innocenti GM. (1986). General Organization of Callosal Connections in the Cerebral Cortex. In: Jones EG, Peters A (eds) Cerebral cortex (vol. 5) Sensory-motor areas and aspects of cortical connectivity. Plenum Press, New York; 1986, p291-353.

[27] Reblet C, López-Medina A, Gómez-Urquijo SM, Bueno-López JL. Widespread horizontal connections arising from layer 5/6 border inverted cells in rabbit visual cortex. European Journal of Neuroscience 1992; 4(3) 221-234, doi:10.1111/j.14609568.1992.tb00870.x

[28] Mendizabal-Zubiaga JL, Reblet C, Bueno-López JL. The underside of the cerebral cortex: layer V/VI spiny inverted neurons. Journal of Anatomy 2007; 211(2) 223-236, doi:10.1111/j.1469-7580.2007.00779.x

[29] Casanovas-Aguilar C, Christensen MK, Reblet C, Martínez-García F, Pérez-Clausell J, Bueno-López JL. Callosal neurons give rise to zinc-rich boutons in the rat visual cortex. NeuroReport 1995; 6(3) 497-500.

[30] Casanovas-Aguilar C, Reblet C, Pérez-Clausell J, Bueno-López JL. Zinc-Rich afferents to the rat neocortex: projections to the visual cortex traced with intracerebral selenite injections. Journal of Chemical Neuroanatomy 1998; 72(2) 97-109, doi:10.1016/S08910618(98)00035-0

[31] Felleman DJ, Van Essen DC. Distributed hierarchical processing in the primate cerebral cortex. Cerebral Cortex 1991; 1(1) 1-47, doi:10.1093/cercor/1.1.1

[32] Coogan TA, Burkhalter A. Hierarchical organization of areas in rat visual cortex. Journal of Neuroscience 1993; 13(9) 3749-3772.

[33] Gutiérrez-Ibarluzea I, Acera-Osa A, Mendizabal-Zubiaga JL, Arana-Arri A, BuenoLópez JL, Reblet C. Morphology and laminar distribution of cortico-claustral neurons in different areas of the rabbit cerebral cortex. European Journal of Anatomy 1999; 3(2) 101-109.

[34] Olavarría J, Van Sluyters RC. Organization and postnatal development of callosal connections in the visual cortex of the rat. Journal of Comparative Neurology 1985; 239(1) 1-26, doi:10.1002/cne.902390102

[35] Innocenti M, Manger PR, Masiello I, Colin I, Tettoni L. Architecture and callosal connections of visual areas 17, 18, 19 and 21 in the ferret (Mustela putorius). Cerebral Cortex 2002; 12(4) 411-422, doi:10.1093/cercor/12.4.411 
[36] Molyneaux BJ, Arlotta P, Fame RM, MacDonald JL, MacQuarrie KL, Macklis JD. Novel subtype-specific genes identify distinct subpopulations of callosal projection neurons. Journal of Neuroscience 2009; 29(39) 12343-12354, doi:10.1523/ JNEUROSCI.610808.2009

[37] Arimatsu Y, Ishida M, Kaneko T, Ichinose S, Omori A. Organization and Development of Corticocortical Associative neurons expressing the orphan nuclear receptor Nurr1. Journal of Comparative Neurology 2003; 466(2) 180-196, doi:10.1002/cne.10875

[38] Mitchel BD, Macklis JD. Large-scale maintenance of dual projections by callosal and frontal cortical projection neurons in adult mice. Journal of Comparative Neurology 2005; 482(1) 17-32, doi:10.1002/cne.20428

[39] Veinante P, Deschênes M. Single-cell study of motor cortex projections to the barrel field in rats. Journal of Comparative Neurology 2003; 464(1) 98 -103, doi:10.1002/cne.10769

[40] Wilson CJ. Morphology and synaptic connections of crossed corticostriatal neurons in the rat. Journal of Comparative Neurology 1987; 263(4) 567-580, doi:10.1002/cne.902630408

[41] Levesque M, Charara A, Gagnon S, Parent A, Deschênes M. Corticostriatal projections from layer $\mathrm{V}$ cells in rat are collaterals of long range corticofugal axons. Brain Research 1996; 709(2) 311-315, doi:10.1016/0006-8993(95)01333-4

[42] Levesque M, Gagnon S, Parent A, Deschênes M. Axonal arborizations of corticostriatal and corticothalamic fibers arising from the second somatosensory area in the rat. Cerebral Cortex 1996; 6(6) 759-770, doi:10.1093/cercor/6.6.759

[43] Levesque M, Parent A. Axonal arborization of corticostriatal and corticothalamic fibers arising from prelimbic cortex in the rat. Cerebral Cortex 1998; 8(7) 602-613, doi:10.1093/cercor/8.7.602

[44] Reiner A, Hart NM, Lei W, Deng Y. Corticostriatal projection neurons-dichotomous types and dichotomous functions. Frontiers in Neuroanatomy 2010. 4(Article142) 1-15, doi:10.3389/fnana.2010.00142

[45] Shoemaker LD, Arlotta P. Untangling the Cortex: Advances in Understanding Specification and Differentiation of Corticospinal Motor Neurons. BioEssays 2010; 32(3) 197-206. Available online 27 January 2010; http://dx.doi.org/10.1002/bies.200900114

[46] Kasper EM, Larkman AU, Lübke J, Blakemore C. Pyramidal neurons in layer 5 of the rat visual cortex. III. Differential maturation of axon targeting, dendritic morphology and electrophysiological properties. Journal of Comparative Neurology 1994; 339(4) 495518, doi:10.1002/cne.903390404

[47] Kita T, Kita H. The subthalamic nucleus is one of multiple innervation sites for longrange corticofugal axons: a single-axon tracing study in the rat. Journal of Neuroscience 2012; 32(17) 5990-5999, doi:10.1523/jneurosci.5717-11.2012

[48] Jones E.G. The thalamic matrix and thalamocortical synchrony. Trends in Neurosciences 2001; 24(10), 595-601, doi:10.1016/S0166-2236(00)01922-6

[49] Rockland KS. Convergence and branching patterns of round, type II corticopulvinar axons. Journal of Comparative Neurology 1998; 390(4) 515-536, doi:10.1002/(SICI)10969861(19980126)390:4<515::AID-CNE5>3.0.CO;2-3 
[50] Veinante P, Lavallé P, Deschênes M. Corticothalamic projections from layer V of the vibrissal barrel cortex in the rat. Journal of Comparative Neurology 2000; 424(2) 197204, doi:0.1002/1096-9861(20000821)424:2<197::AID-CNE1>3.0.CO;2-6

[51] Guillery RW, Sherman SM. Thalamic relay functions and their role in corticocortical communication: generalizations from the visual system. Neuron 2002; 33(2) 163-175, doi:10.1016/S0896-6273(01)00582-7

[52] Hallman LE, Schofield BR, Lin CS. Dendritic morphology and axon collaterals of corticotectal, cortico-pontine, and callosal neurons in layer $\mathrm{V}$ of the primary visual cortex of the hooded rat. Journal of Comparative Neurology 1990; 272(1) 149-160, doi:10.1002/cne.902720111

[53] Otsuka T, Kawaguchi Y. Cortical inhibitory cell types differentially form intralaminar and interlaminar subnetworks with excitatory neurons. Journal of Neuroscience 2009; 29(34) 10533-10540, doi:10.1523/jneurosci.2219-09.2009

[54] Brown SP, Hestrin S. Intracortical circuits of pyramidal neurons reflect their long-range axonal targets. Nature 2009; 457(-) 1133-1136, doi:10.1038/nature07658

[55] Kiritani T, Wickersham IR, Seung HS, Shepherd GMG. Hierarchical connectivity and connection-specific dynamics in the corticospinal-corticostriatal microcircuit in mouse motor cortex. Journal of Neuroscience 2012; 32(14) 4992-5001, doi:10.1523/ jneurosci.4759-11.2012

[56] Morishima M, Morita K, Kubota Y, Kawaguchi Y. Highly differentiated projectionspecific cortical subnetworks. Journal of Neuroscience 2011; 31(28) 10380-10391, doi:10.1523/jneurosci.0772-11.2011

[57] Otsuka T, Kawaguchi Y. Cell diversity and connection specifity between callosal projection neurons in the frontal cortex. Journal of Neuroscience 2011; 31(10) 3862-3870, doi:10.1523/jneurosci.5795-10.2011

[58] Binzegger T, Douglas RJ, Martin KAC. A quantitative map of the circuit of cat primary visual cortex. Journal of Neuroscience 2004; 24(39) 8441- 8453, doi:10.1523/ jneurosci.1400-04.2004

[59] Guillery RW. Anatomical pathways that link perception and action. In: Progress in Brain Research. Elsevier BV. 2005; 149(Chapter 17) 235-256, doi:10.1016/S00796123(05)49017-2

[60] Thomson A.M. Neocortical layer 6, a review. Frontiers in Neuroanatomy 2010; 4(13) 414, doi:10.3389/fnana.2010.00013

[61] Molnár G, Oláh S, Komlósi G, Füle M, Szabadics J, Varga C, Barzo P, Tamás, G. Complex events initiated by individual spikes in the human cerebral cortex. PLoS Biology September 2008; 6(9):e222, doi:10.1371/journal.pbio.0060222

[62] Woodruff A, Yuste R. State-dependent function of neocortical chandelier cells. Journal of Neuroscience 2011; 31(49), 17872-17886, doi:10.1523/jneurosci.3894-11.2011

[63] Gilbert CD, Wiesel TN. Columnar specificity of intrinsic horizontal and corticocortical connections in cat visual cortex. Journal of Neuroscience 1989; 9(7), 2432-2442.

[64] Kisvárday ZF, Eysel UT. Cellular organization of reciprocal patchy networks in layer III of cat visual cortex area 17. Neuroscience 1992; 46(2) 275-286, doi: 10.1016/03064522(92)90050-C 
[65] Burkhalter A. Intrinsic connections of rat primary visual cortex: laminar organization of axonal projections. Journal of Comparative Neurology 1989; 279(2) 171-186, doi: 10.1002/cne.902790202

[66] Markov NT, Misery P, Falchier A, Lamy C, Vezoli J, Quilodran R, Gariel MA, Giroud P, Ercsey-Ravasz M, Pilaz LJ, Huissoud C, Barone P, Dehay C, Toroczkai Z, Van Essen DC, Kennedy H, Knoblauch K. Weight consistency specifies regularities of macaque cortical networks. Cerebral Cortex 2011; 21(6) 1254-1272, doi: 10.1093/cercor/bhq201

[67] Douglas RJ, Martin KAC. Recurrent neuronal circuits in the neocortex. Current Biology 2007; 17(13) R496-R500.

[68] Galarreta M, Hestrin S. A network of fast-spiking cells in the neocortex connected by electrical synapses. Nature 1999; 402(-), 72-75, doi:10.1038/47029

[69] Fukuda T, Kosaka T, Singer W, Galuske RAW. Gap junctions among dendrites of cortical GABAergic neurons establish a dense and widespread intercolumnar network. Journal of Neuroscience 2006; 26(13) 3434 -3443, doi: 10.1523/jneurosci.4076-05.2006

[70] Simon A, Oláh S, Molnár G, Szabadics J, Tamás G. Gap-junctional coupling between neurogliaform cells and various interneuron types in the neocortex. Journal of Neuroscience 2005; 25(27) 6278-6285, doi:10.1523/jneurosci.1431-05.2005

[71] Bartos M, Vida I, Jonas P. (2007). Synaptic mechanisms of synchronized gamma oscillations in inhibitory interneuron networks. Nature Reviews Neuroscience 2007; 8(-) 45-56, doi:10.1038/nrn2044

[72] Klausberger T, Magill PJ, Márton LF, Roberts JD, Cobden PM, Buzsáki G, Somogyi P. Brain-state- and cell-type-specific firing of hippocampal interneurons in vivo. Nature 2003; 421(6925) 844-848.

[73] Grubb MS, Shu Y, Kuba H, Rasband MN, Wimmer VC, Bender, KJ. Short- and longterm plasticity at the axon initial segment. Journal of Neuroscience 2011; 31(45), 1604916055, doi:10.1523/jneurosci.4064-11.2011

[74] Lorincz A, Nusser Z. Cell-type-dependent molecular composition of the axon initial segment. Journal of Neuroscience 2008; 28(53) 14329-14340, doi: 10.1523/jneurosci.483308.2008

[75] Grubb MS, Burrone J. Activity-dependent relocation of the axon initial segment finetunes neuronal excitability. Nature 2010; 465(-) 1070-1076, doi:10.1038/nature09160

[76] Inda MC, DeFelipe J, Muñoz A. Voltage-gated ion channels in the axon initial segment of human cortical pyramidal cells and their relationship with chandelier cells. PNAS 2006; 103(8) 2920-2925, doi:10.1073/pneas.05111971.03

[77] Hu W, Tian C, Yang M, Hou H, Shu Y. Distinct contributions of Nav1.6 and Nav1.2 in action potential initiation and backpropagation. Nature Neuroscience 2009; 12(-) 9961002, doi:10.1038/nn.2359

[78] Palmer LM, Stuart GJ. Site of action potential initiation in layer 5 pyramidal neurons. Journal of Neuroscience 2006; 26(6) 1854-1863, doi: 10.1523/jneurosci.4812-05.2006

[79] Shu Y, Duque A, Yu Y, Haider B, McCormick, D. Properties of action-potential initiation in neocortical pyramidal cells: evidence from whole cell axon recordings. Journal of Neurophysiology 2007; 97(1) 746-760, doi:10.1152/jn.00922.2006 
[80] Perez-Reyes E. Molecular physiology of low-voltage-activated t-type calcium channels. Physiological Reviews 2003; 83(1) 117-161, doi:10.1152/physrev.00018.2002

[81] Bender KJ, Ford CP, Trussell LO. Dopaminergic modulation of axon initial segment calcium channels regulates action potential initiation. Neuron 2010; 68(3) $500-511$, 10.1016/j.neuron.2010.09.026

[82] DeFelipe J, Hendry SH, Hashikawa T, Jones EG. Synaptic relationships of serotoninimmunoreactive terminal baskets on GABA neurons in the cat auditory cortex. Cerebral Cortex 1991; 1(2) 117-133.

[83] Dianne A, Cruz MS, Stephen M, Eggan BS, Efrain C, Azmitia Ph.D, David A, Lewis MD. Serotonin $1 \mathrm{~A}$ receptors at the axon initial segment of prefrontal pyramidal neurons in schizophrenia. American Journal of Psychiatry 2004; 161(4) 739-742, doi: 10.1176/appi.ajp.161.4.739

[84] Peters A, Proskauer CC, Kaiserman-Abramof IR. The small pyramidal neuron of the rat cerebral cortex. The axon hillock and initial segment. Journal of Cell Biology 1968; 39(3) 604-619.

[85] Somogyi P, Freund TF, Cowey A. The axo-axonic interneuron in the cerebral cortex of the rat, cat and monkey. Neuroscience 1982; 7(11) 2577-607, doi:10.1016/03064522(82)90086-0

[86] Fariñas I, DeFelipe J. Patterns of synaptic input on corticocortical and corticothalamic cells in the cat visual cortex. II. The axon initial segment. Journal of Comparative Neurology 1991; 304(1) 70-77, doi: 10.1002/cne.903040106

[87] Ogawa Y, Horresh I, Trimmer JS, Bredt DS, Peles E, Rasband MN. Postsynaptic density93 Clusters $K_{v} 1$ channels at axon initial segments independently of Caspr2. Journal of Neuroscience 2008; 28(22) 5731-5739, doi: 10.1523/jneurosci.4431-07.2008

[88] Davis JQ, Bennet V. Ankyrin binding activity shared by the neurofascin/L1/NrCAM family of nervous system cell adhesion molecules. Journal of Biological Chemistry 1994; 269(44) 27163-27166.

[89] Hedstrom KL, Ogawa Y, Rasband MN. AnkiyrinG is required for maintenance of the axon initial segment and neuronal plasticity. Journal of Cell Biology 2008; 183(4) 635640, doi:10.1083/jcb.200806112

[90] Meeks JP, Mennerick S. Action potential initiation and propagation in CA3 pyramidal axons. Journal of Neurophysiology 2007; 97(5) 3460-3472, doi:10. 1152/jn.01288. 2006

[91] Schmidt-Hieber C, Bischofberger J. Fast sodium channel gating supports localized and efficient axonal action potential initiation. Journal of Neuroscience 2010; 30(30) 1023310242, doi:10.1523/jneurosci.6335-09.2010

[92] Krees GJ, Dowling MJ, Meeks JP, Mennerick S. High threshold, proximal initiation, and slow conduction velocity of action potentials in dentate granule neuron mossy fibers. Journal of Neurophysiology 2008; 100(1) 281-291, doi:10.1152/jn.90295.2008

[93] Chara JC. Estudio paramétrico ultrastructural del segmento inicial del axon de las neuronas piramidales supra e infragranulares con proyección axonal identificada en la corteza visual de la rata. Tesis doctoral. Universidad del País Vasco (UPV/EHU); 2010. 
[94] Sloper JJ, Powell TPS. A study of the axon initial segment and proximal axon of neurons in the primate motor cortex y somatic sensory cortices. Philosophical Transactions of the Royal Society of London 1979. Series B, Biological Sciences 285(1006) 173-197.

[95] DeFelipe J, Hendry SCH, Jones EG, Schmechel D. Variability in the terminations of GABAergic chandelier cell axons on initial segments of pyramidal cell axons in the monkey sensory-motor cortex. Journal of Comparative Neurology 1985; 231(3) 364-384, 10.1002/cne.902310307

[96] Fairén A, Valverde F. A specialized type of neuron in the visual cortex of the cat: a Golgi and electron microscope study of chandelier cells. Journal of Comparative Neurology 1980; 194(4) 761-779, doi:10.1002/cne.901940405

[97] Matute C, Contamina P, Martinez-Millán L. The axon initial segment of corticocollicular neurons in the rabbit visual cortex: An electron-microscope study with HRP. Histology and Histopathology 1987; 2(-) 147-151.

[98] Fried SI, Lasker ACW, Desail NJ, Eddington DK, Rizzo 3rd JF. Axonal sodium-channel bands shape the response to electric stimulation in retinal ganglion cells. Journal of Neurophysiology 2009; 10(4) 1972-1987, doi:10.1152/jn.91081.2008

[99] Konishi M. Coding of auditory space. Annual Review Neuroscience 2003; 26(-) 31-55, doi: 10.1146/annurev.neuro.26.041002.131123

[100] Kuba H, Ishii TM, Ohmori H. Axonal site of spike initiation enhances auditory coincidence detection. Nature 2006; 444(-) 1069-1072, doi:10.1038/nature05347

[101] Kuba H, Oichi Y, Ohmori H. Presynaptic activity regulates $\mathrm{Na}^{+}$channel distribution at the axon initial segment. Nature 2010; 465(-) 1075-1078, doi:10.1038/nature09087 